\title{
Better Efficacy of Ramucirumab in Japanese Patients than in the Global Population with Unresectable Hepatocellular Carcinoma
}

\author{
Masatoshi Kudo \\ Department of Gastroenterology and Hepatology, Kindai University Faculty of Medicine, \\ Osaka-Sayama, Japan
}

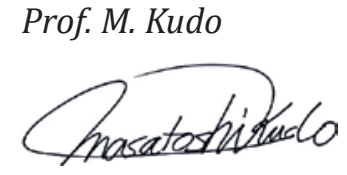

Editor Liver Cancer

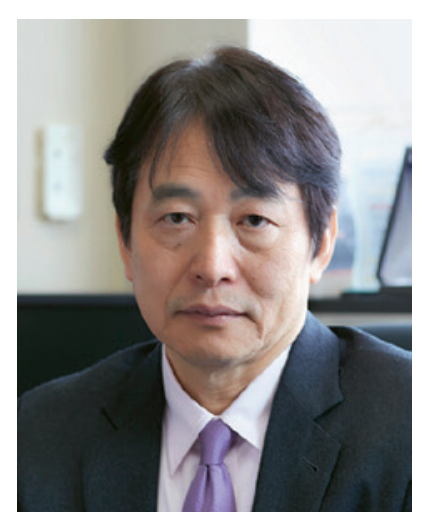

Ramucirumab is a human monoclonal antibody against vascular endothelial growth factor receptor (VEGFR)-2 that has been clinically tested as a second-line treatment in patients with hepatocellular carcinoma (HCC) who progressed on or are intolerant to sorafenib [1]. The REACH trial (REACH) did not show significant improvement in overall survival (OS) in the ramucirumab arm over the placebo group in the overall global population; however, subgroup analysis showed a clear survival benefit in patents with an $\alpha$-fetoprotein (AFP) level $\geq 400 \mathrm{ng} / \mathrm{mL}$, which was not observed in patients with AFP $<400 \mathrm{ng} / \mathrm{mL}$ [2]. In the subsequent REACH-2 trial (REACH-2), which involved only patients with AFP $\geq 400 \mathrm{ng} / \mathrm{mL}$, ramucirumab significantly improved OS over placebo [3]. In Japan, ramucirumab was approved on June 18,2019, for the treatment of patients with HCC aggravated after systemic therapy and AFP $\geq 400 \mathrm{ng} / \mathrm{mL}$. This was the fourth approved indication for ramucirumab after stomach cancer, colorectal cancer, and lung cancer. This article summarizes the factors underlying the greater efficacy of ramucirumab as second-line treatment for HCC in the Japanese population than in the global population despite showing a similar safety profile and tolerability in both groups. 
Kudo: Efficacy of Ramucirumab in Japanese Patients

\section{Subgroup Analysis of the Japanese Population in REACH}

The results of the subgroup analysis of the Japanese population in REACH are reported in detail elsewhere [4]. The results of the REACH trial showed that there was no significant improvement in OS in the overall global population (intention-to-treat analysis), whereas subgroup analysis showed a significantly longer OS in the Japanese population treated with ramucirumab than in the placebo group (12.9 vs. 8.0 months; hazard ratio [HR]: 0.621; $95 \%$ confidence interval [CI], 0.39-0.99; $p=0.0416$ ) (Table 1) [4]. Both OS and progression-free survival (PFS) were better in the Japanese cohort than in the global cohort despite similar baseline characteristics in the two cohorts in the ramucirumab arm, including macrovascular invasion and baseline AFP level, which are strong poor prognostic factors [5, 6] (Table 1). Subgroup analysis in other regional cohorts did not show a significant improvement in OS by ramucirumab unlike the results in the Japanese cohort in the intention-to-treat population.

PFS was also significantly longer in the ramucirumab group (4.1 months) than in the placebo group (1.7 months) in the Japanese cohort (HR: 0.449; 95\% CI, 0.285-0.706; $p=$ 0.0004 ), which showed better values than the global cohort (Table 1). In patients with AFP $\geq 400 \mathrm{ng} / \mathrm{mL}$, OS was considerably longer in the Japanese cohort (12.9 months) than in the global cohort (7.8 months) in patients treated with ramucirumab, whereas OS in the placebo arm was similar between the two cohorts ( 4.3 and 4.2 months, respectively) (Table 2). HR in Japanese patients was 0.464 , whereas that in the global cohort was 0.674 (Table 2).

With respect to adverse events, the Japanese population in REACH showed a favorable profile: the only adverse events with a grade $\geq 3$ occurring at a rate of $\geq 10 \%$ involved hepatic impairment (23\%), and those occurring at a rate of $<10 \%$ included hypertension ( $9 \%$ ), ascites $(7 \%)$, and hemorrhage (7\%). The duration of therapy (12-13 weeks) and dose intensity (98\%) were comparable between the Japanese cohort and the global cohort (Table 3). In summary, REACH showed that the dose intensity of ramucirumab and the occurrence of adverse events were comparable between the Japanese population and the global population, and that ramucirumab has a good safety profile and a better OS benefit in the Japanese population than that in the global cohort.

Because body weight is lower and age is higher in the Japanese population, dose modification results in a lower relative dose intensity (RDI) of tyrosine kinase inhibitors (TKIs) [7-11] in Japanese patients than in the overall population (Table 4). However, unlike previous clinical trials of TKIs, the RDI of ramucirumab was extremely high (98\%) and comparable to that in the global population $[3,4,7,8,12,13]$ (Table 4).

Similar to the findings in the global population, ramucirumab extended OS in patients with AFP $\geq 400 \mathrm{ng} / \mathrm{mL}$, but not in those with AFP $<400 \mathrm{ng} / \mathrm{mL}$, in the Japanese population [4]. This could be attributed to the extension of postprogression survival achieved through aggressive posttrial treatment in patients who received placebo in Japan.

\section{Subgroup Analysis of the Japanese Population in REACH-2}

The overall results of REACH-2 were positive [3]. In the subgroup analysis, the Japanese population of REACH-2 showed a median OS of 10.2 months in the ramucirumab group compared with 5.4 months in the placebo group (HR: 0.599; 95\% CI, 0.303-1.187, $p=0.1377$ ). OS and HR were more favorable in the Japanese population than in the overall global population (OS: 10.2 vs. 8.5 months, respectively, and HR: 0.599 vs. 0.710 , respectively) [14] (Table 5) despite a higher baseline AFP in the Japanese cohort $(7,942 \mathrm{ng} / \mathrm{mL})$ than in the global cohort (3,920 ng/mL) (Table 5). Similarly, PFS in the Japanese cohort was 4.1 months in the ramucirumab arm and 1.7 months in the placebo group (HR: 0.282; 95\% CI, 0.144-0.553; $p<$

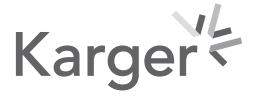




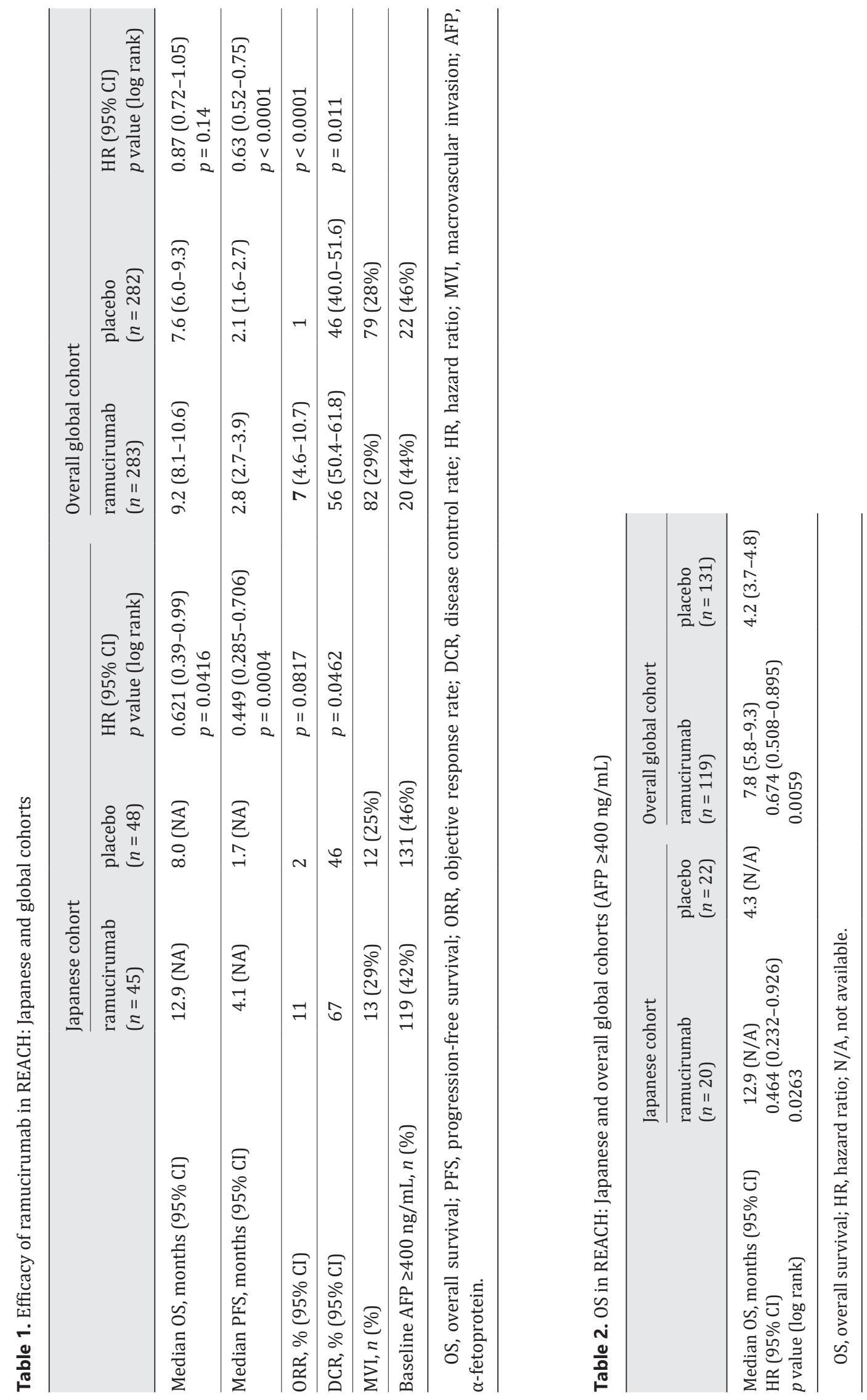




\begin{tabular}{l|l}
\hline \multicolumn{2}{l}{ Liver Cancer 2020;9:232-244 } \\
\hline DOI: 10.1159/000507889 & $\begin{array}{l}\text { @ 2020 The Author(s). Published by S. Karger AG, Basel } \\
\text { www.karger.com/lic }\end{array}$ \\
\hline
\end{tabular}

Table 3. Duration of therapy and relative dose intensity in REACH: Japanese and overall global cohorts

\begin{tabular}{|c|c|c|c|c|}
\hline & \multicolumn{2}{|c|}{ Japanese cohort } & \multicolumn{2}{|c|}{ Overall global cohort } \\
\hline & $\begin{array}{l}\text { ramucirumab } \\
(n=44)\end{array}$ & $\begin{array}{l}\text { placebo } \\
(n=47)\end{array}$ & $\begin{array}{l}\text { ramucirumab } \\
(n=277)\end{array}$ & $\begin{array}{l}\text { placebo } \\
(n=276)\end{array}$ \\
\hline \multicolumn{5}{|l|}{ Duration of therapy, weeks } \\
\hline Median & 13 & 8 & 12 & 8 \\
\hline Minimum-maximum & $2-128$ & $2-68$ & $2-128$ & $2-146$ \\
\hline \multicolumn{5}{|l|}{ Relative dose intensity, \% } \\
\hline Median & 98 & 100 & 98 & 99 \\
\hline Minimum-maximum & $67-106$ & $66-113$ & $39-109$ & $62-113$ \\
\hline \multicolumn{5}{|c|}{ Relative dose intensity, $n(\%)$} \\
\hline$<60 \%$ & 0 & 0 & $1(1 \%)$ & 0 \\
\hline $60-<80 \%$ & $3(7 \%)$ & $2(4 \%)$ & $19(7 \%)$ & 7 (3\%) \\
\hline $80-<90 \%$ & $4(9 \%)$ & $1(2 \%)$ & $27(10 \%)$ & $11(4 \%)$ \\
\hline $90-<110 \%$ & $37(84 \%)$ & $43(91 \%)$ & $230(83 \%)$ & $256(93 \%)$ \\
\hline$\geq 110 \%$ & 0 & $1(2 \%)$ & 0 & $2(1 \%)$ \\
\hline
\end{tabular}

Table 4. Relative dose intensity (RDI) of molecular targeted agents

\begin{tabular}{|c|c|c|c|c|c|c|c|}
\hline \multirow{2}{*}{\multicolumn{2}{|c|}{$\begin{array}{l}\text { Monoclonal antibody } \\
\text { ramucirumab (median) }[3,4]\end{array}$}} & \multicolumn{6}{|l|}{ TKI } \\
\hline & & \multicolumn{2}{|c|}{ lenvatinib (mean) $[7,12]$} & \multicolumn{2}{|c|}{ sorafenib (mean) $[7,12]$} & \multicolumn{2}{|c|}{ regorafenib (mean) $[8,13]$} \\
\hline $\begin{array}{l}\text { Japanese } \\
\text { cohort }\end{array}$ & $\begin{array}{l}\text { overall } \\
\text { global cohort }\end{array}$ & $\begin{array}{l}\text { Japanese } \\
\text { cohort }\end{array}$ & $\begin{array}{l}\text { overall } \\
\text { global cohort }\end{array}$ & $\begin{array}{l}\text { Japanese } \\
\text { cohort }\end{array}$ & $\begin{array}{l}\text { overall } \\
\text { global cohort }\end{array}$ & $\begin{array}{l}\text { Japanese } \\
\text { cohort }\end{array}$ & $\begin{array}{l}\text { overall } \\
\text { global cohort }\end{array}$ \\
\hline $98 \%$ & $98 \%$ & $75 \%$ & $88 \%$ & $70 \%$ & $83 \%$ & $84 \%$ & $91 \%$ \\
\hline
\end{tabular}

TKI, tyrosine kinase inhibitor; RDI, ramucirumab (overall global cohort) = ramucirumab (Japanese cohort); RDI, ramucirumab (overall global/Japanese) > TKI (overall global cohort) > TKI (Japanese cohort).

0.0001; Table 5) [14]. These results were more favorable than those obtained in the global cohort (PFS = 2.8 months; HR = 0.452). The safety profile in Japanese population was extremely favorable too: the only adverse events with a grade $\geq 3$ were hypertension in 6 patients (14.6\%) and loss of appetite in 2 patients (4.9\%). Liver function impairment was observed in 11 patients (26.8\%), of which $3(7.3 \%)$ presented with $\geq$ grade 3 liver dysfunction [14].

\section{Results of Pooled Analysis from REACH (Patients with AFP $\geq 400 \mathrm{ng} / \mathrm{mL}$ Only) and REACH-2: Japanese and Global Cohorts}

The results of pooled analysis in REACH (AFP $\geq 400 \mathrm{ng} / \mathrm{mL}$ ) and REACH-2 were reported for both the Japanese and global cohorts (Table 6) [3, 14]. The OS of the placebo arm was shorter in REACH (AFP $\geq 400 \mathrm{ng} / \mathrm{mL}$ ) (4.2 months) than in REACH-2 (7.3 months), which may be attributed to the considerably higher AFP value $(7,022 \mathrm{ng} / \mathrm{mL}$ ) in REACH (AFP $\geq 400 \mathrm{ng}$ / $\mathrm{mL}$ ) as compared with that $(2,741 \mathrm{ng} / \mathrm{mL}$ ) in REACH-2 (Table 6).

Pooled analysis of the Japanese cohorts showed an OS benefit with ramucirumab, with a median OS of 10.8 months in the ramucirumab arm compared with 4.5 months in the placebo arm (HR: $0.555 ; 95 \%$ CI, $0.348-0.885 ; p=0.0124$ ). In addition, PFS was significantly longer in the ramucirumab arm than in the placebo group (3.9 vs. 1.4 months, respectively; 

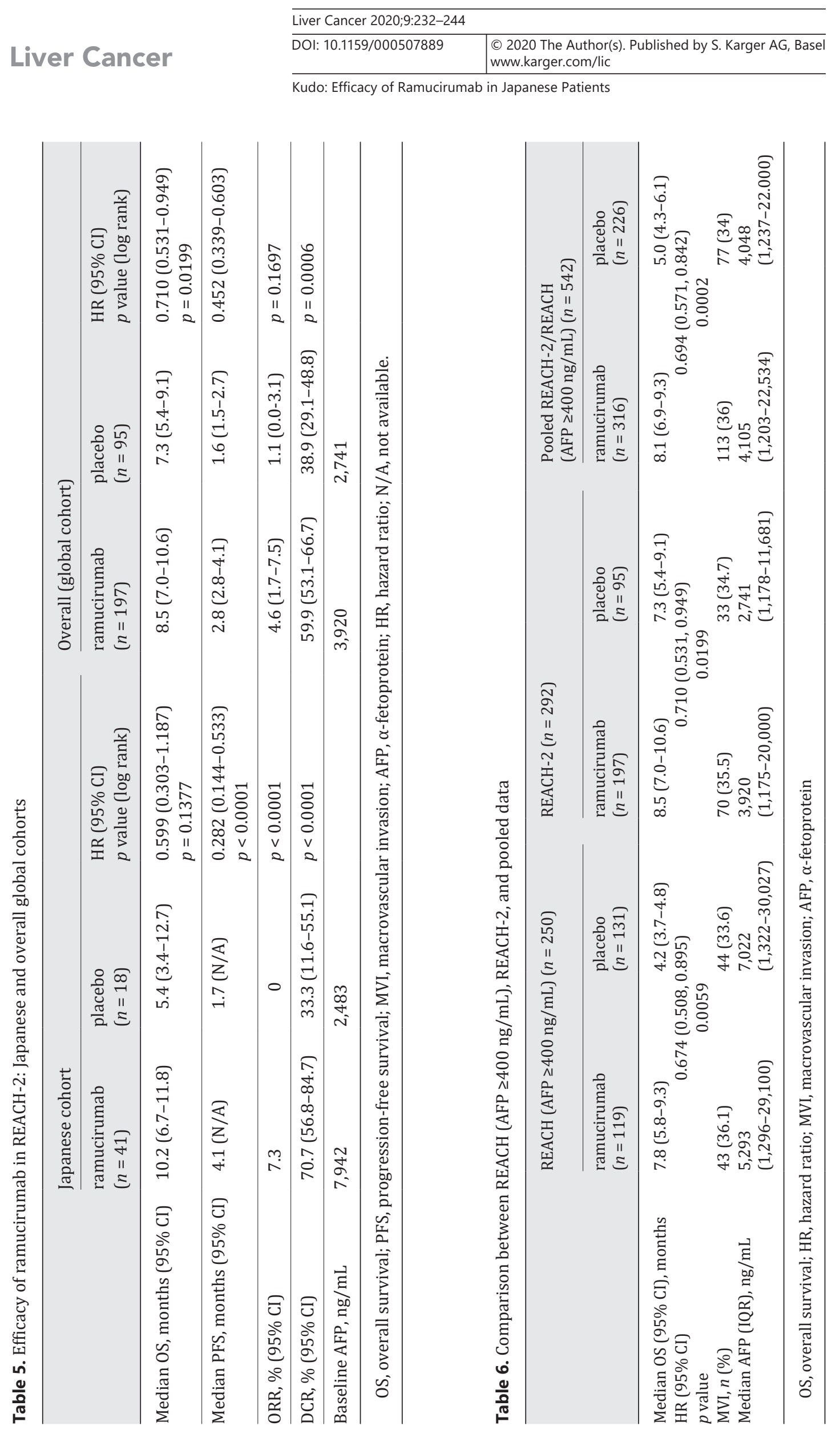


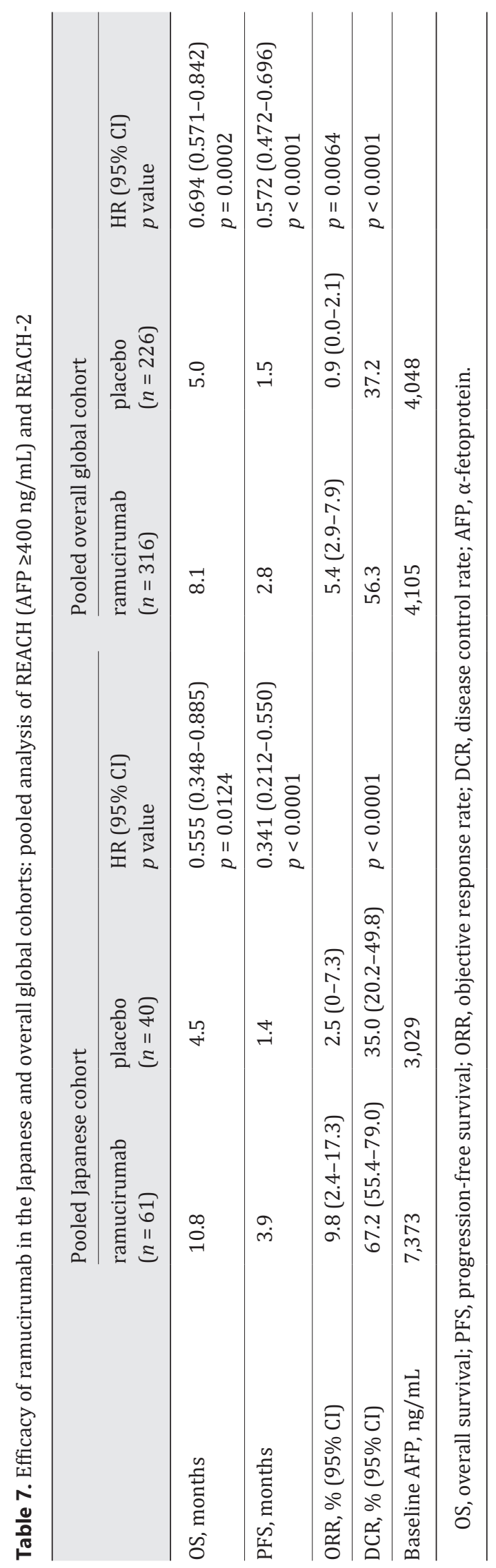




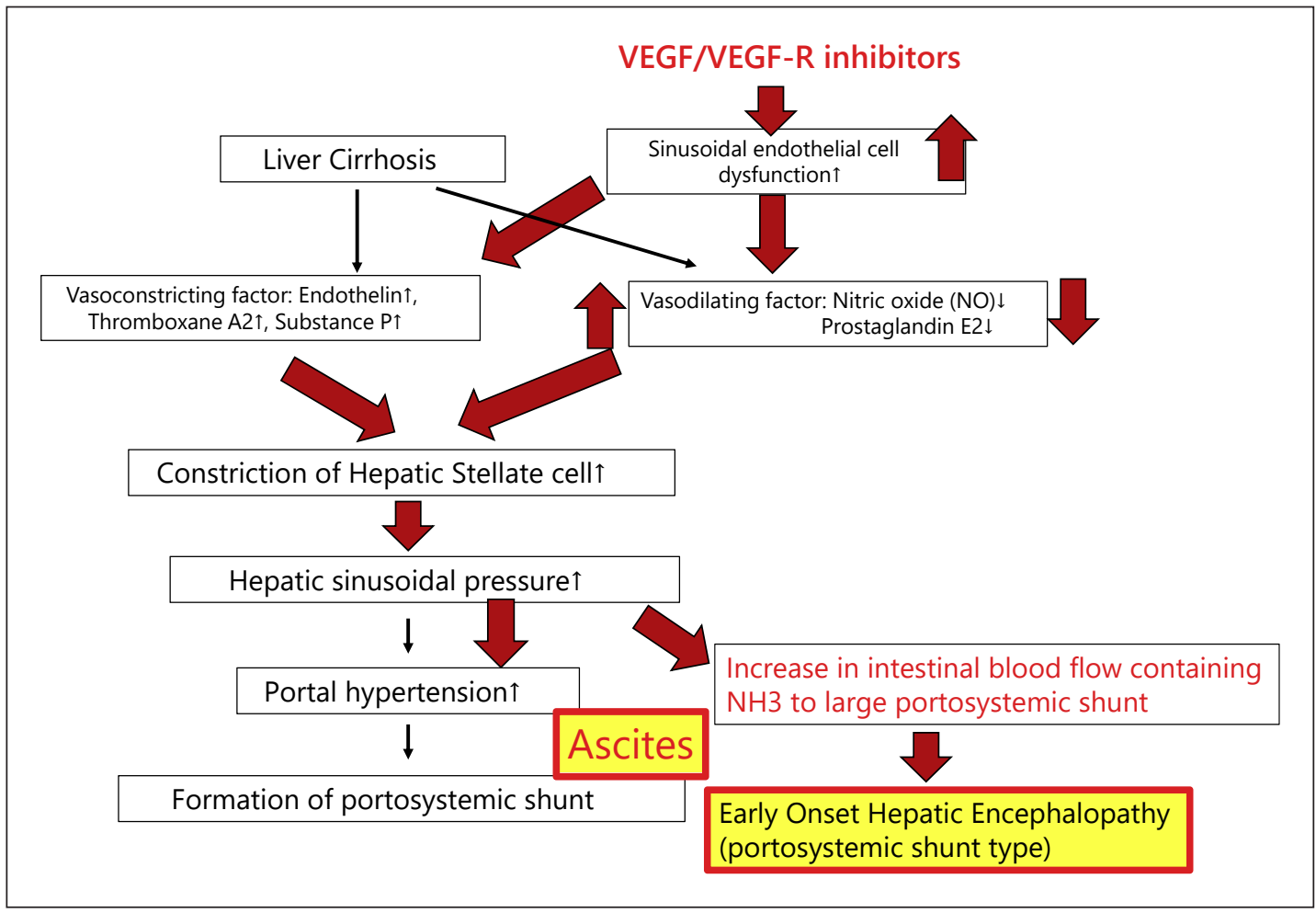

Fig. 1. Mechanism underlying the occurrence of serious adverse events, such as ascites or hepatic encephalopathy, in patients treated with ramucirumab. The strong inhibitory effect of ramucirumab on VEGFR-2 leads to increased hepatic stellate pressure because of the upregulation of vasoconstricting factors and the downregulation of vasodilating factors, resulting in portal hypertension. A preexisting large portosystemic shunt may lead to shunt type hepatic encephalopathy. In the absence of large collaterals, ascites may occur.

HR: $0.341 ; 95 \%$ CI, 0.212-0.550; $p<0.0001$; Table 7). Both OS and PFS were longer in the pooled Japanese cohort than in the pooled global cohort (OS: 10.8 vs. 8.1 months; PFS: 3.9 vs. 2.8 months) despite a higher baseline AFP level in the Japanese cohort $(7,373 \mathrm{ng} / \mathrm{mL})$ than in the global cohort $(4,105 \mathrm{ng} / \mathrm{mL}$ ) (Table 7). Similarly, OS HR and PFS HR were better in the Japanese cohort than in the global cohort (OS HR: 0.555 vs. 0.694; PFS HR: 0.341 vs. 0.572 ).

In the Japanese cohort, the objective response rate determined by RECIST 1.1 was $9.8 \%$ in the ramucirumab arm (95\% CI, 2.4-17.3) compared with $2.5 \%$ in the placebo arm (95\% CI, 0-7.3), with a disease control rate of $67.2 \%$ in the ramucirumab arm (55.4-79.0) and $35.0 \%(20.2-49.8)$ in the placebo arm. These results were more favorable than the corresponding results in the overall global population despite a higher baseline AFP level in the Japanese cohort $(7,373 \mathrm{ng} / \mathrm{mL})$ than in the global cohort $(4,105 \mathrm{ng} / \mathrm{mL}$ ) (Table 6) $[3,14]$.

In the Japanese cohort, the only grade $\geq 3$ adverse events observed were hypertension in 7 patients (12\%) and ascites in 2 patients (3\%). However, hemorrhagic events were found in 3 patients (5\%) and hepatic impairment in 15 patients (25\%). Two patients (3\%) had ascites and 3 patients (5\%) had hepatic encephalopathy among those with hepatic impairment [14]; this could be attributed to the effect of VEGFR-2 inhibition on increasing hepatic sinusoidal pressure, which may increase portal vein pressure (Fig. 1). 


\begin{tabular}{|c|c|}
\hline \multicolumn{2}{|c|}{ Liver Cancer 2020;9:232-244 } \\
\hline DOI: 10.1159/000507889 & $\begin{array}{l}\text { (c) } 2020 \text { The Author(s). Published by S. Karger AG, Basel } \\
\text { www.karger.com/lic }\end{array}$ \\
\hline
\end{tabular}

Table 8. Rate of BCLC stage B and C in REACH, REACH-2, and pooled analysis

\begin{tabular}{|c|c|c|c|c|c|c|c|c|c|}
\hline & \multicolumn{3}{|l|}{ REACH } & \multicolumn{3}{|l|}{ REACH-2 } & \multicolumn{3}{|c|}{$\begin{array}{l}\text { Pooled (REACH [AFP } 400 \mathrm{ng} / \mathrm{mL}]+ \\
\text { REACH-2) }\end{array}$} \\
\hline & $\begin{array}{l}\text { Japanese } \\
(n=93)\end{array}$ & $\begin{array}{l}\text { non- } \\
\text { Japanese }\end{array}$ & $\begin{array}{l}\text { overall } \\
(n=565)\end{array}$ & $\begin{array}{l}\text { Japanese } \\
(n=59)\end{array}$ & $\begin{array}{l}\text { non- } \\
\text { Japanese }\end{array}$ & $\begin{array}{l}\text { overall } \\
(n=292)\end{array}$ & $\begin{array}{l}\text { Japanese } \\
(n=101)\end{array}$ & $\begin{array}{l}\text { non- } \\
\text { Japanese }\end{array}$ & $\begin{array}{l}\text { overall } \\
(n=542)\end{array}$ \\
\hline \multirow[t]{3}{*}{ BCLC B } & \multicolumn{3}{|c|}{$p=0.046$} & \multicolumn{3}{|c|}{$p=0.529$} & \multicolumn{3}{|c|}{$p=0.063$} \\
\hline & \multicolumn{2}{|c|}{$p=0.014$} & & \multicolumn{2}{|c|}{$p=0.433$} & & \multicolumn{2}{|c|}{$p=0.021$} & \\
\hline & $\begin{array}{l}19.4 \% \\
(18 / 93)\end{array}$ & $\begin{array}{l}11.5 \% \\
(49 / 472)\end{array}$ & $\begin{array}{l}11.9 \% \\
(67 / 565)\end{array}$ & $\begin{array}{l}20.2 \% \\
(13 / 59)\end{array}$ & $\begin{array}{l}17.6 \% \\
(41 / 233)\end{array}$ & $\begin{array}{l}18.4 \% \\
(54 / 292)\end{array}$ & $\begin{array}{l}20.7 \% \\
(21 / 101)\end{array}$ & $\begin{array}{l}12.0 \% \\
(53 / 441)\end{array}$ & $\begin{array}{l}13.6 \% \\
(74 / 542)\end{array}$ \\
\hline BCLC C & $\begin{array}{l}80.6 \% \\
(75 / 93)\end{array}$ & $\begin{array}{l}89.6 \% \\
(423 / 472)\end{array}$ & $\begin{array}{l}88.1 \% \\
(498 / 565)\end{array}$ & $\begin{array}{l}78.0 \% \\
(46 / 59)\end{array}$ & $\begin{array}{l}82.4 \% \\
(192 / 233)\end{array}$ & $\begin{array}{l}81.6 \% \\
(238 / 292)\end{array}$ & $\begin{array}{l}79.3 \% \\
(80 / 101)\end{array}$ & $\begin{array}{l}88.0 \% \\
(388 / 441)\end{array}$ & $\begin{array}{l}86.4 \% \\
(468 / 542)\end{array}$ \\
\hline
\end{tabular}

Table 9. Efficacy of ramucirumab in pooled data (REACH $[\mathrm{AFP} \geq 400 \mathrm{ng} / \mathrm{mL}]$ ) and REACH-2

\begin{tabular}{|c|c|c|c|c|}
\hline & \multicolumn{2}{|l|}{ BCLC stage B } & \multicolumn{2}{|l|}{ BCLC stage $\mathrm{C}$} \\
\hline & $\begin{array}{l}\text { ramucirumab } \\
(n=30)\end{array}$ & $\begin{array}{l}\text { placebo } \\
(n=22)\end{array}$ & $\begin{array}{l}\text { ramucirumab } \\
(n=286)\end{array}$ & $\begin{array}{l}\text { placebo } \\
(n=204)\end{array}$ \\
\hline Median OS, months & 13.7 & 8.2 & 7.7 & 4.8 \\
\hline $\operatorname{HR}(95 \% \mathrm{CI})$ & \multicolumn{2}{|c|}{$0.43(0.23-0.83)$} & \multicolumn{2}{|c|}{$0.72(0.59-0.89)$} \\
\hline Median PFS, months & \multirow[t]{2}{*}{4.2} & 2.8 & \multirow[t]{2}{*}{2.8} & \multirow{2}{*}{$\begin{array}{l}1.5 \\
-0.74)\end{array}$} \\
\hline $\mathrm{HR}(95 \% \mathrm{CI})$ & & $0.33(0.17-0.64)$ & & \\
\hline ORR, $\%$ & 17 & 5 & 4 & 1 \\
\hline DCR, \% & 80 & 59 & 54 & 35 \\
\hline
\end{tabular}

OS, overall survival; PFS, progression-free survival; ORR, objective response rate; DCR, disease control rate; $\mathrm{HR}$, hazard ratio.

\section{Possible Reasons for the Better Efficacy of Ramucirumab in Japanese Patients}

The greater efficacy of ramucirumab in Japanese patients may be associated with the high number of patients with BCLC stage B enrolled in the REACH and REACH-2 trials [2-4, 14] (Table 8). In the REACH trial, 19.4\% (18/93) of enrolled patients in the Japanese cohort was BCLC stage B HCC, as compared with $11.5 \%(49 / 472)$ in the non-Japanese cohort ( $p=0.014)$ and $11.9 \%(67 / 565)$ in the overall cohort $(p=0.046)$. In pooled data, $20.7 \%(21 / 101)$ in the Japanese cohort were BCLC stage B HCC as compared with $12.0 \%(53 / 441)$ in the nonJapanese cohort ( $p=0.021)$ and 13.6\% (74/542) in the overall cohort ( $p=0.063)$ (Table 8). Patients with BCLC stage B have a better OS (13.7 months) than those with BCLC stage C (7.7 months) in the ramucirumab treated group in the pooled global population (Table 9) [15]. The HR for OS is also better in BCLC stage B $(0.43$; 95\% CI, 0.23-0.83) than in BCLC stage C patients $(0.72 ; 95 \%$ CI, 0.59-0.89) (Table 9) [15]. Similarly, PFS is longer in BCLC stage B patients (4.2 months) than in BCLC stage C patients (2.8 months). The HR for PFS is also better in BCLC stage B patients $(0.33$; $95 \% \mathrm{CI}, 0.17-0.64)$ than in BCLC stage C patients $(0.60 ; 95 \%$ CI, 0.49-0.74) [15] (Table 9). Therefore, the greater number of BCLC stage B patients enrolled in REACH and pooled cohort in Japanese patients (Table 8) may have resulted in a greater efficacy of ramucirumab in Japanese patients than in the global cohort. In REACH-2, there was no difference in the ratio of BCLC B stage between the Japanese, non-Japanese, and overall cohorts. However, more patients with baseline ALBI score 1 were observed in the Japanese 
Table 10. Baseline ALBI score and Child-Pugh score in REACH-2 and pooled data: comparison between the Japanese, non-Japanese and overall global cohorts

\begin{tabular}{|c|c|c|c|c|c|c|c|}
\hline & & \multicolumn{3}{|l|}{ REACH-2 } & \multicolumn{3}{|c|}{$\begin{array}{l}\text { Pooled (REACH [AFP } 400 \mathrm{ng} / \mathrm{mL}]+ \\
\text { REACH-2) }\end{array}$} \\
\hline & & $\begin{array}{l}\text { Japanese } \\
(n=59)\end{array}$ & $\begin{array}{l}\text { non-Japanese } \\
(n=233)\end{array}$ & $\begin{array}{l}\text { overall } \\
(n=292)\end{array}$ & $\begin{array}{l}\text { Japanese } \\
(n=101)\end{array}$ & $\begin{array}{l}\text { non-Japanese } \\
(n=433)\end{array}$ & $\begin{array}{l}\text { overall } \\
(n=534)^{\mathrm{a}}\end{array}$ \\
\hline & & \multicolumn{3}{|c|}{$p=0.054$} & \multicolumn{3}{|c|}{$p=0.955$} \\
\hline & & & $=0.018$ & & & $=0.945$ & \\
\hline \multirow[t]{4}{*}{$\begin{array}{l}\text { Baseline ALBI } \\
\text { score }\end{array}$} & 1 & $\begin{array}{l}62.7 \% \\
(37 / 59)\end{array}$ & $\begin{array}{l}45.5 \% \\
(106 / 233)\end{array}$ & $\begin{array}{l}49.0 \% \\
(143 / 292)\end{array}$ & $\begin{array}{l}43.6 \% \\
(44 / 101)\end{array}$ & $\begin{array}{l}43.2 \% \\
(187 / 433)\end{array}$ & $\begin{array}{l}42.6 \% \\
(231 / 534)\end{array}$ \\
\hline & 2 & $\begin{array}{l}37.3 \% \\
(22 / 59)\end{array}$ & $\begin{array}{l}52.4 \% \\
(122 / 233)\end{array}$ & $\begin{array}{l}49.3 \% \\
(144 / 292)\end{array}$ & $\begin{array}{l}53.5 \% \\
(54 / 101)\end{array}$ & $\begin{array}{l}55.9 \% \\
(242 / 433)\end{array}$ & $\begin{array}{l}55.4 \% \\
(296 / 534)\end{array}$ \\
\hline & & \multicolumn{3}{|c|}{$p=0.820$} & \multicolumn{3}{|c|}{$p=0.301$} \\
\hline & & & $=0.853$ & & & $=0.143$ & \\
\hline \multirow[t]{2}{*}{$\begin{array}{l}\text { Child-Pugh } \\
\text { score }\end{array}$} & 5 & $\begin{array}{l}59.3 \% \\
(35 / 59)\end{array}$ & $\begin{array}{l}60.9 \% \\
(142 / 233)\end{array}$ & $\begin{array}{l}60.6 \% \\
(177 / 292)\end{array}$ & $\begin{array}{l}54.5 \% \\
(55 / 101)\end{array}$ & $\begin{array}{l}62.4 \% \\
(270 / 433)\end{array}$ & $\begin{array}{l}60.0 \% \\
(325 / 542)\end{array}$ \\
\hline & 6 & $\begin{array}{l}40.7 \% \\
(24 / 59)\end{array}$ & $\begin{array}{l}39.1 \% \\
(91 / 233)\end{array}$ & $\begin{array}{l}39.4 \% \\
(115 / 292)\end{array}$ & $\begin{array}{l}43.6 \% \\
(44 / 101)\end{array}$ & $\begin{array}{l}38.6 \% \\
(167 / 433)\end{array}$ & $\begin{array}{l}38.9 \% \\
(211 / 534)\end{array}$ \\
\hline
\end{tabular}

a There were 8 cases categorized as ALBI grade 3 and 6 cases categorized as Child-Pugh score 7 or 8 .

than in the non-Japanese cohort ( 62.7 vs. $45.5 \%, p=0.018$ ). This might have contributed to the better efficacy of ramucirumab treatment in Japanese patients than non-Japanese patients in REACH-2 trial (Table 10) [16-18].

Another possible reason could be differences in the method used for measuring serum albumin level between Japan and other countries. Since 2000, most hospitals in Japan measure serum albumin levels using the modified bromocresol purple (BCP) assay, which is more accurate than the widely used conventional method, bromocresol green (BCG), used in most of other countries. The modified BCP method has been adopted in most University Hospitals in Japan because it is a more accurate method to measure serum albumin level than the old method, BCG, which is still used in many other countries. Comparing serum albumin levels obtained using the BCG method should be done with caution, especially in patients with chronic kidney disease and liver cirrhosis. In cirrhotic patients, serum albumin level measured with the modified BCP method has been shown to be significantly lower (approximately 0.3 $\mathrm{g} / \mathrm{dL}$ lower, but actually accurate albumin level) than that obtained with the BCG method. The method used to measure serum albumin (BCG or modified BCP) changes the Child-Pugh score in $20-30 \%$ of cases [19-22]. Therefore, caution is necessary in global clinical trials that include Japan because a Child-Pugh score of 5 or 6 determined by the modified BCP method in Japan represents better liver function than a Child-Pugh score of 5 or 6 measured by the BCG method in most of other countries.

In the ramucirumab-treated group, OS is better in patients with ALBI grade 1 than in those with ALBI grade 2 (11.4 vs. 5.8 months, respectively) [17,23], and OS is better in patients with Child-Pugh score 5 than in those with Child-Pugh score 6 (10.6 vs. 6.1 months, respectively) in ramucirumab-treated patients (Table 11) [17]. Similarly, in ramucirumab-treated patients, the HR for PFS is better in ALBI grade $1(0.425)$ than in ALBI grade $2(0.730)$, and better in Child-Pugh score 5 (0.543) than in Child-Pugh score $6(0.634)$ patients [17]. The better efficacy of ramucirumab in Japanese patients may be attributed to the use of different serum albumin measurement methods in Japan (modified BCP method). True liver function may be better in Japanese patients than overall global patients even though both groups show 
Table 11. Ramucirumab OS benefit in pooled REACH-2/REACH (AFP $\geq 400 \mathrm{ng} / \mathrm{mL}$ ) according to ALBI grade and Child-Pugh score

\begin{tabular}{|c|c|c|c|c|}
\hline & \multicolumn{4}{|l|}{ ALBI grade } \\
\hline & \multicolumn{2}{|l|}{ grade 1} & \multicolumn{2}{|l|}{ grade 2} \\
\hline & ramucirumab & placebo & ramucirumab & placebo \\
\hline \multirow{6}{*}{$\begin{array}{l}\text { Median OS, months } \\
\text { HR }(95 \% \text { CI) } \\
p \text { value (log rank) }\end{array}$} & 11.4 & 6.6 & 5.8 & 4.2 \\
\hline & \multirow{2}{*}{\multicolumn{2}{|c|}{$\begin{array}{c}0.605(0.445-0.824) \\
0.0013\end{array}$}} & \multirow{2}{*}{\multicolumn{2}{|c|}{$\begin{array}{c}0.830(0.540-1.076) \\
0.1626\end{array}$}} \\
\hline & & & & \\
\hline & \multicolumn{4}{|c|}{ Child-Pugh score } \\
\hline & \multicolumn{2}{|l|}{ CP-5 } & \multicolumn{2}{|l|}{ СР-6 } \\
\hline & ramucirumab & placebo & ramucirumab & placebo \\
\hline Median OS, months & 10.6 & 6.4 & 6.1 & 4.1 \\
\hline HR $(95 \%$ CI) & \multirow{2}{*}{\multicolumn{2}{|c|}{$\begin{array}{c}0.646(0.499-0.836) \\
0.0008\end{array}$}} & \multirow{2}{*}{\multicolumn{2}{|c|}{$\begin{array}{c}0.719(0.531-0.974) \\
0.0343\end{array}$}} \\
\hline$p$ value (log rank) & & & & \\
\hline
\end{tabular}

Cited from Brandi et al. [17].

the same ALBI grade or Child-Pugh score since serum albumin level measured by BCG method is overestimated in other countries, where BCG method is used as compared with modified BCP method, which is used in Japan.

\section{Ramucirumab in the Treatment of Japanese HCC Patients}

Ramucirumab is more effective (e.g., OS, PFS, and response rate) in Japanese patients than in the overall global population according to the REACH and REACH-2 trials and pooled data from REACH- 2 and REACH (AFP $\geq 400 \mathrm{ng} / \mathrm{mL}$ ). In addition to the results of the REACH trial, the results of the REACH-2 trial are of particular interest because of the inclusion of Japan as an independent stratification factor. Therefore, the characteristics of the different populations were relatively well balanced in the ramucirumab and placebo arms in the REACH-2 Japanese subpopulation.

The safety profile of ramucirumab is similar in the Japanese population and the overall global population, indicating that ramucirumab is well tolerated even in the elderly Japanese population. Indeed, ramucirumab is effective and well tolerated in elderly patients $>75$ years of age [24], which is the most common age subgroup of patients with HCC in Japan.

The tolerability of ramucirumab is better than that of other TKIs with an acceptable dose intensity (Table 4) $[3,4,7,8,12,13]$. Therefore, the dose intensity of ramucirumab is higher than that of any existing TKI (sorafenib, lenvatinib, and regorafenib) in both the overall population and the Japanese population $[3,4,7,8,12,13]$ (Table 4).

\section{Comparison of OS HR between Second-Line Agents}

Ramucirumab shows extremely high efficacy, safety, and tolerability in elderly Japanese patients, suggesting that it is a promising agent for the treatment of HCC [25]. Table 12 shows the results of the comparison of OS HR between ramucirumab and other second-line agents 
Table 12. Hazard ratio of OS among second-line agents

\begin{tabular}{|c|c|c|c|}
\hline Trial & $\begin{array}{l}\text { All cohort (any AFP) } \\
\text { HR ( } 95 \% \text { CI) } \\
\text { drug vs. placebo } \\
\text { [median OS, months] }\end{array}$ & $\begin{array}{l}\text { AFP } \geq 400 \\
\text { HR }(95 \% \text { CI }) \\
\text { drug vs. placebo } \\
\text { [median OS, months] }\end{array}$ & Ref. \\
\hline RESORCE (regorafenib) & $\begin{array}{l}0.63(0.50-0.79) \\
{[10.6 \text { vs. } 7.8]}\end{array}$ & $\begin{array}{l}0.68(0.50-0.92) \\
{[N / A]}\end{array}$ & 8 \\
\hline CELESTIAL (cabozantinib) & $\begin{array}{l}0.76(0.63-0.72) \\
{[10.2 \text { vs. } 8.0]}\end{array}$ & $\begin{array}{l}0.71(0.54-0.94) \\
{[8.5 \text { vs. 5.2] }}\end{array}$ & 26 \\
\hline $\begin{array}{l}\text { REACH-2 } \\
\text { (ramucirumab, AFP } \geq 400 \text { ) }\end{array}$ & $\mathrm{N} / \mathrm{A}$ & $\begin{array}{l}0.71(0.53-0.95) \\
{[8.5 \text { vs. } 7.3]}\end{array}$ & 3 \\
\hline $\begin{array}{l}\text { REACH-2 } \\
\text { (ramucirumab, AFP } \geq 400 \text { ) } \\
\text { Japanese subpopulation }\end{array}$ & $\mathrm{N} / \mathrm{A}$ & $\begin{array}{l}0.60(0.30-1.19) \\
{[10.2 \text { vs. } 5.4]}\end{array}$ & 14 \\
\hline $\begin{array}{l}\text { REACH+REACH- } 2 \\
\text { (ramucirumab, AFP } \geq 400 \text { ) } \\
\text { Pooled data (global population) }\end{array}$ & $\mathrm{N} / \mathrm{A}$ & $\begin{array}{l}0.69(0.57-0.84) \\
{[8.1 \text { vs. } 5.0]}\end{array}$ & 3 \\
\hline $\begin{array}{l}\text { REACH+REACH-2 } \\
\text { (ramucirumab, AFP } \geq 400 \text { ) } \\
\text { Pooled data (Japanese subpopula }\end{array}$ & $\mathrm{N} / \mathrm{A}$ & $\begin{array}{l}0.56(0.35-0.89) \\
{[10.8 \text { vs. } 4.5]}\end{array}$ & 14 \\
\hline
\end{tabular}

N/A, not available.

(regorafenib and cabozantinib) in patients with AFP $\geq 400 \mathrm{ng} / \mathrm{mL}[3,8,14,26]$. The $\mathrm{HR}$ for OS in patients with AFP $\geq 400 \mathrm{ng} / \mathrm{mL}$ was most favorable (HR: 0.56 ; $95 \% \mathrm{CI}, 0.35-0.89$ ) in the Japanese pooled data (REACH [AFP $\geq 400 \mathrm{ng} / \mathrm{mL}$ ] and REACH-2) among second-line agents.

\section{Conclusion}

The results of REACH, REACH-2, the pooled analysis, and Japanese subpopulation analysis indicate that ramucirumab is more effective in Japanese patients than in the overall global HCC population and can be considered a promising second-line therapy in Japanese patients with unresectable HCC.

\section{Disclosure Statement}

Lectures: Eisai, Bayer, MSD, Eli Lilly; Grants: EA Pharma, Eisai, Gilead, Takeda, Otsuka, Taiho; Advisory Consulting: Eisai, Ono, MSD, BMS, Roche, AstraZeneca, Eli Lilly.

\section{Funding Sources}

None. 


\begin{tabular}{l|l}
\hline Liver Cancer 2020;9:232-244 \\
\hline DOI: 10.1159/000507889 & $\begin{array}{l}\text { @ 2020 The Author(s). Published by S. Karger AG, Basel } \\
\text { www.karger.com/lic }\end{array}$ \\
\hline
\end{tabular}

\section{References}

1 Bouattour M, Mehta N, He AR, Cohen EI, Nault JC. Systemic Treatment for Advanced Hepatocellular Carcinoma. Liver Cancer. 2019 0ct;8(5):341-58.

2 Zhu AX, Park JO, Ryoo BY, Yen CJ, Poon R, Pastorelli D, et al.; REACH Trial Investigators. Ramucirumab versus placebo as second-line treatment in patients with advanced hepatocellular carcinoma following first-line therapy with sorafenib (REACH): a randomised, double-blind, multicentre, phase 3 trial. Lancet Oncol. 2015 Jul;16(7):859-70.

3 Zhu AX, Kang YK, Yen CJ, Finn RS, Galle PR, Llovet JM, et al.; REACH-2 study investigators. Ramucirumab after sorafenib in patients with advanced hepatocellular carcinoma and increased $\alpha$-fetoprotein concentrations (REACH-2): a randomised, double-blind, placebo-controlled, phase 3 trial. Lancet Oncol. 2019 Feb;20(2):28296.

4 Kudo M, Hatano E, Ohkawa S, Fujii H, Masumoto A, Furuse J, et al. Ramucirumab as second-line treatment in patients with advanced hepatocellular carcinoma: japanese subgroup analysis of the REACH trial. J Gastroenterol. 2017 Apr;52(4):494-503.

5 Kudo M, Izumi N, Kubo S, Kokudo N, Sakamoto M, Shiina S, et al. Report of the 20th nationwide follow-up survey of primary liver cancer in Japan. Hepatol Res. 2020;50:15-46.

6 Zhu AX, Finn RS, Galle PR, Llovet JM, Kudo M. Ramucirumab in advanced hepatocellular carcinoma in REACH-2: the true value of $\alpha$-fetoprotein. Lancet Oncol. 2019 Apr;20(4):e191.

7 Kudo M, Finn RS, Qin S, Han KH, Ikeda K, Piscaglia F, et al. Lenvatinib versus sorafenib in first-line treatment of patients with unresectable hepatocellular carcinoma: a randomised phase 3 non-inferiority trial. Lancet. 2018 Mar;391(10126):1163-73.

8 Bruix J, Qin S, Merle P, Granito A, Huang YH, Bodoky G, et al.; RESORCE Investigators. Regorafenib for patients with hepatocellular carcinoma who progressed on sorafenib treatment (RESORCE): a randomised, doubleblind, placebo-controlled, phase 3 trial. Lancet. 2017 Jan;389(10064):56-66.

9 Kudo M. Lenvatinib may drastically change the treatment landscape of hepatocellular carcinoma. Liver Cancer. 2018 Mar; 7(1):1-19.

10 Kudo M. Cabozantinib as a Second-Line Agent in Advanced Hepatocellular Carcinoma. Liver Cancer. 2018 May; $7(2): 123-33$.

11 Kudo M. Extremely High Objective Response Rate of Lenvatinib: Its Clinical Relevance and Changing the Treatment Paradigm in Hepatocellular Carcinoma. Liver Cancer. 2018 Sep;7(3):215-24.

12 Yamashita T, Kudo M, Ikeda K, Izumi N, Tateishi R, Ikeda M, et al. REFLECT-a phase 3 trial comparing efficacy and safety of lenvatinib to sorafenib for the treatment of unresectable hepatocellular carcinoma: an analysis of Japanese subset. J Gastroenterol. 2020 Jan;55(1):113-22.

13 Yokosuka O, Meinhardt G, Bruix J. Regorafenib as second-line treatment for patients with HCC who progressed on sorafenib: Japanese subgroup analysis of the phase 3 RESORCE trial. JSH Annual Meeting, PD1-12, 2017.

14 Kudo M, Okusaka T, Motomura K, Ohno I, Morimoto M, Seo S, et al. Ramucirumab after prior sorafenib in patients with advanced hepatocellular carcinoma and elevated alpha-fetoprotein: japanese subgroup analysis of the REACH-2 trial. J Gastroenterol. 2020 Feb. https://doi.org/10.1007/s00535-020-01668-w.

15 Kudo M, Finn RS, Morimoto M, Rau KM, Ikeda M, Yen CJ, et al. Ramucirumab for patients with intermediatestage hepatocellular carcinoma (HCC) and elevated alpha fetoprotein (AFP): Pooled results from two phase III studies (REACH and REACH-2). 2020 Gastrointeritinal Cancers Symposium (ASCO-GI 2020), San Francisco, January 23-25, 2020.

16 Kudo M, Galle PR, Brandi G, Kang YK, Yen CJ, Finn RS, et al. Effect of ramucirumab on albumin-bilirubin grade in patients with hepatocellular carcinoma and elevated alpha-fetoprotein following sorafenib treatment: exploratory analysis of two randomized phase 3 studies (REACH, REACH-2). ILCA 13th Annual Conference, September 20-22, 2019, Chicago (Abst \#p-066).

17 Brandi G, Kudo M, Kang Y, Yen C, Finn RS, Galle PR, et al. Ramucirumab for patients with hepatocellular carcinoma and elevated alpha-fetoprotein following sorafenib treatment: exploratory analysis of REACH-2 trial results by albumin-bilirubin grade and Child-Pugh score. EASL HCC Summit 2019, Lisbon, February 14-16, 2019.

18 Ikeda M, Zhu AX, Okusaka T, Motomura K, Morimoto M, Seo S, et al. Effect of ALBI score by ramucirumab for patients with hepatocellular carcinoma and elevated alpha-fetoprotein following sorafenib treatment: analysis of Japanse subgroup of REACH and REACH-2. The 21st Japan Association of Molecular Targeted Therapy for HCC, National Cancer Center Japan, Tokyo, January 11, 2020.

19 Muramoto Y, Matsushita M, Irino T. Reduction of reaction differences between human mercaptalbumin and human nonmercaptalbumin measured by the bromcresol purple method. Clin Chim Acta. 1999;289:69-78.

20 Seimiya M, Ohno S, Yamamoto H, Fujiwara K, Yoshida T, Sawabe Y, et al. Child-Pugh score is altered by the albumin measurement method. Hepatology. 2013 May;57(5):2093-4.

21 Ono M, Aoki Y, Masumoto M, Hotta T, Uchida Y, Kayamori Y, et al. High-dose penicillin G-treatment causes underestimation of serum albumin measured by a modified BCP method. Clin Chim Acta. 2009;407:75-76.

22 Watanabe A, Matsuzaki S, Moriwaki H, Suzuki K, Nishiguchi S. Problems in serum albumin measurement and clinical significance of albumin microheterogeneity in cirrhotics. Nutrition. 2004 Apr;20(4):351-7. 
23 Hiraoka A, Kumada T, Michitaka K, Kudo M. Newly Proposed ALBI Grade and ALBI-T Score as Tools for Assessment of Hepatic Function and Prognosis in Hepatocellular Carcinoma Patients. Liver Cancer. 2019 Oct; 8(5):312-25.

24 Kudo M, Galle PR, Motomura K, Assenat E, Merle P, Brandi G, et al. Efficacy and safety of ramucirumab (RAM) for advanced hepatocellular carcinoma (HCC) with elevated alpha-fetoprotein (AFP) following first-line sorafenib across age subgroups in two global phase III trials (REACH and REACH-2). ESMO 2019, Barcelona, September 27-October 1.

25 Kudo M. Ramucirumab as Second-Line Systemic Therapy in Hepatocellular Carcinoma. Liver Cancer. 2018 Oct; $7(4): 305-11$.

26 Abou-Alfa GK, Meyer T, Cheng AL, El-Khoueiry AB, Rimassa L, Ryoo BY, et al. Cabozantinib in Patients with Advanced and Progressing Hepatocellular Carcinoma. N Engl J Med. 2018 Jul;379(1):54-63. 